\title{
High-resolution melting curve analysis for high-throughput genotyping of NOD2/CARD15 mutations and distribution of these mutations in Slovenian inflammatory bowel diseases patients
}

\author{
Mitja Mitrovič ${ }^{\mathrm{a}}$ and Uroš Potočnik ${ }^{\mathrm{a}, \mathrm{b}, *}$ \\ ${ }^{a}$ Faculty of Medicine, Center for Human Molecular Genetics and Pharmacogenomics, University of Maribor, \\ Maribor, Slovenia \\ ${ }^{\mathrm{b}}$ Faculty of Chemistry and Chemical Engineering, University of Maribor, Maribor, Slovenia
}

\begin{abstract}
Inflammatory bowel diseases (IBD) are usually classified into Crohn's disease (CD) and ulcerative colitis (UC). NOD2/CARD15 was the first identified CD-susceptibility gene and was confirmed as the most potent disease gene in CD pathogenesis. Three NOD2/CARD15 variants, namely two missense polymorphisms R702W (rs2066844) and G908R (rs2066845), and a frame shift polymorphism L1007fs (rs2066847), were associated with CD in Caucasian populations. High resolution melting analysis (HRMA) with saturation LCGreen dyes was previously reported as a simple, inexpensive, accurate and sensitive method for genotyping and/or scanning of rare variants. For this reasons we used qPCR-HRMA for genotyping NOD2/CARD15 variants in 588 Slovenian IBD patients and 256 healthy controls. PCR-RFLP was used as a reference method for genotyping of clinical samples. The optimization of an HRM experiment required careful design and adjustment of main parameters, such as primer concentration, $\mathrm{MgCl}_{2}$ concentration, probe design and template DNA concentration. Different HRMA approaches were tested and used to develop a reliable and low-cost SNP genotyping assays for polymorphisms in NOD2/CARD15 gene. Direct HRMA was the fastest and cheapest HRMA approach for L1007fs and R702W polymorphisms, yet for G908R polymorphism sufficient reliability was achieved after introduction of unlabeled probe. In association analysis, we found statistically significant association of L1007fs $(p=0.001, \mathrm{OR}=3.011, \mathrm{CI} 95 \%=1.494-6.071)$ and G908R $\left(p=2.62 \times 10^{-4}, \mathrm{OR}=14.117, \mathrm{C} 195 \%=\right.$ 1.884-105.799) polymorphisms with CD patients. At least one of NOD2/CARD15 polymorphisms was found in 78/354 (22.03\%) in CD patients, $25 / 197$ (12.69\%) in UC patients and in 26/256 (10.15\%) in healthy controls. We have successfully implemented NOD2/CARD15 HRMA assays, which may contribute to the development of genetic profiles for risk prediction of developing $\mathrm{CD}$ and for differential diagnosis of $\mathrm{CD}$ vs. UC.
\end{abstract}

Keywords: High-resolution melting analysis, NOD2/CARD15, inflammatory bowel diseases

\section{List of abbreviations}

$\begin{array}{ll}\text { CD } & \text { Crohn's disease } \\ \text { DMSO } & \text { Dimethyl sulfoxide } \\ \text { DSA } & \text { Disease-susceptibility allele } \\ \Delta \mathrm{T}_{m} & \begin{array}{l}\text { Difference in melting temperatures (e.g. between } \\ \text { C/C and T/T) }\end{array} \\ \text { HPLC } & \text { High-performance liquid chromatography }\end{array}$

* Corresponding author: Assoc. Prof. Uroš Potočnik, PhD, Tel.: +38 623305874; Fax: +38 623305861; E-mail: uros.potocnik@unimb.si.

$\begin{array}{ll}\text { HRMA } & \text { High resolution melting analysis } \\ \text { IC } & \text { Indeterminate colitis } \\ \text { IBD } & \text { Inflammatory bowel disease } \\ \text { MAF } & \text { Minor allele frequency } \\ \text { OR } & \text { Odds ratio } \\ \text { PCR } & \text { Polymerase chain reaction } \\ \text { qPCR } & \text { Quantitative (real-time) PCR } \\ \text { RFLP } & \text { Restriction fragment length polymorphism } \\ \text { SNP } & \text { Single nucleotide polymorphism } \\ \text { Tm } & \text { Melting temperature } \\ \text { UC } & \text { Ulcerative colitis }\end{array}$




\section{Introduction}

Inflammatory bowel diseases (IBD) are usually classified into Crohn's disease (CD) and ulcerative colitis (UC). In a recent genome-wide association study, three NOD2/CARD15 disease susceptibility alleles (DSAs), namely two missense polymorphisms R702W (rs2066844) and G908R (rs2066845), and a frame shift polymorphism L1007fs (rs2066847), have shown the most significant association with CD [1]. In addition to $\mathrm{CD}, N O D 2 / C A R D 15$ polymorphisms might also play important role in Blau syndrome [2] and graft-versushost disease [3]. Therefore a high-throughput and costeffective genotyping method is needed for diagnostic screening of NOD2/CARD15 DSAs. There are several conventional genotyping methods available, but most of them require a post-PCR separation step which is time-consuming and also increases the risk of contamination of PCR products [4]. On the other hand, most of the close-tube methods require expensive fluorescently labeled probes [5] or primers [6]. High-resolution melting analysis (HRMA) was introduced as a closedtube genotyping method, where the post-PCR separation step is avoided [7,8]. HRMA also offers significant savings, ease of use and increased sample throughput, compared to other screening methods $[9,10]$. Although HRMA enables the detection of heterozygotes and most homozygotes, in some cases an unlabeled probe has to be introduced to enhance homozygote discrimination [4]. Unlabeled probes are usually introduced when the difference in melting temperatures $(\mathrm{Tm})$ between two homozygotes is small $\left(0.00-0.25^{\circ} \mathrm{C}\right)$ [11]. HRMA was previously described as a powerful diagnostic method for polymorphism scanning in several clinically important genes [12-14]. However, no HRMA assays for NOD2/CARD15 DSAs have been reported to this date. Therefore, our primary aim was to design and optimize NOD2/CARD15 HRMA genotyping assays and to evaluate the genotyping efficiency of qPCR-HRMA by comparing it to the conventional PCR-RFLP genotyping method. In addition we report the distribution of NOD2/CARD15 DSAs in Slovenian general population and in IBD patients.

\section{Materials and methods}

\subsection{Experimental subjects and DNA extraction}

We analyzed genotyping results of 588 Slovenian IBD patients including $354 \mathrm{CD}$ patients, $197 \mathrm{UC}$ pa- tients and 37 patients with intermediate colitis, as well as 256 healthy unrelated blood donors as a control group. Patients were enrolled in the study as described previously [15]. In this study $49 \%$ of IBD patients were male and $51 \%$ were female. Mean age of IBD patients was 38.6 years and mean age at diagnosis was 27.17 years. Experiments were undertaken with the understanding and written consent of each individual, and the study conforms with The Code of Ethics of the World Medical Association (Declaration of Helsinki) [16]. Study was also approved by the Ethical Committee of the Republic of Slovenia. Genomic DNA of 255 IBD patients and 256 healthy controls was extracted from whole blood lymphocytes, according to manufacturer's protocol, using a combination of FicollPaque PLUS (GE Healthcare Bio-Sciences, Sweden) and TRI REAGENT (Sigma-Aldrich, USA) reagents. DNA samples of 333 IBD patients were extracted from paraffin-embedded biopsy sections after tissue digestion, using standard phenol/chloroform extraction and ethanol precipitation as described previously [15].

\subsection{Design of primers and unlabeled probe}

Primers and unlabeled probe were designed with Primer3 software [17] and synthesized by standard phosphoramidite chemistry (Invitrogen, USA). Several factors were taken into account during design of the primers. Sequence variations were positioned at the center of amplicons. Primers used in PCR-RFLP of G908R variant produced 223 bp amplicon which was inappropriate for qPCR-HRMA since sample genotypes could not be distinguished in melting analysis. Thus, we designed primers for G908R variant that resulted in $100 \mathrm{bp}$ amplicon. Additionally, because nearest neighbor thermodynamic model [18] predicts no difference of melting temperatures for $\mathrm{G}: \mathrm{C}$ transition in G908R variant, we expected indistinct separation of homozygous wild-type vs. homozygous mutant melting curves. Therefore we designed unlabeled probe which was blocked on the 3'-hydroxyl terminus with a three carbon (C3) alkyl group to prevent extension by Taq polymerase during PCR. Sequences of primers, probe and amplicon lengths for NOD2/CARD15 DSAs are shown in Table 1.

\subsection{PCR-RFLP optimization}

PCR-RFLP was used to obtain reference genotypes from CEPH DNA samples and from DNA samples of 588 patients and 256 healthy controls. PCR-RFLP optimization parameters are summarized in Table 2. 
Table 1

Primers and probe used for PCR amplification

\begin{tabular}{llc}
\hline SNP & Primer and probe sequence 5'-3' & Amplicon length (bp) \\
\hline L1007fs (rs2066847) & F: CTGGCTAACTCCTGCAGT & 217 \\
& R: ACTGAGGTTCGGAGAGCT & \\
G908R (rs2066845) & F*: GGTCCACTTTGCTGGGACCA & 100 \\
& R*: TCACCCAAGGCTTCAGCCAG & \multirow{2}{*}{223} \\
& F: GGTCCACTTTGCTGGGACCA & \\
& R: TCACCCAAGGCTTCAGCCAG & \\
& P: ATTCTGGCGCAACAGAGTG & \\
R702W (rs2066844) & F: TTCCTGGCAGGGCTGTTGC & \\
& R: AGTGGAAGTGCTTGCGGAGG & \\
\hline
\end{tabular}

$\mathrm{F}$, forward primer;

$\mathrm{R}$, reverse primer;

$\mathrm{P}$, unlabeled probe;

The underlined base in the probe sequence indicates the position of the variation.

* Primers used only for PCR-HRMA.

Table 2

PCR-RFLP parameters

\begin{tabular}{lccc}
\hline PCR-RFLP reaction parameter & \multicolumn{2}{c}{ Value } \\
\cline { 2 - 4 } & L1007fs & G908R & R702W \\
\hline Annealing temperature $\left[{ }^{\circ} \mathrm{C}\right]$ & 57 & 58 & 63 \\
Primer concentration $[\mathrm{nM}]$ & 187 & 250 & 187 \\
Final c(MgC12) $[\mathrm{mM}]$ & 3 & 2 & 2 \\
Vol. / vol. DMSO added [\%] & 0 & 0 & 5 \\
Cycles & 35 & 35 & 35 \\
Restriction enzyme [units] (enzyme name) & $0.5($ Bsp LI) & $0.5($ Hha I) & 1 (Msp I) \\
Cleavage time $37^{\circ} \mathrm{C}[$ hours] & 4 & 4 & 4 \\
Restriction fragments [bp] & wt/wt: $217, \mathrm{C} / \mathrm{C}: 180+37$ & $\mathrm{C} / \mathrm{C}: 172+51, \mathrm{G} / \mathrm{G}: 223$ & $\mathrm{C} / \mathrm{C}: 21+54+58, \mathrm{~T} / \mathrm{T}: 21+112$ \\
\hline
\end{tabular}

Table 3

qPCR-HRMA optimization parameters and optimal values

\begin{tabular}{lcccc}
\hline Optimization parameter & Tested values & \multicolumn{3}{c}{ Optimal value } \\
\cline { 3 - 5 } qPCR-HRMA & & L1007fs & G908R & R702W \\
\hline Annealing temperature $\left[{ }^{\circ} \mathrm{C}\right]$ & $55-65$ & 57 & 60 & 63 \\
Primer concentration $[\mathrm{nM}]$ & $125-500$ & 187 & 250 & 187 \\
Final c(MgCl2) $[\mathrm{mM}]$ & $1.5 ; 2 ; 2.5 ; 3$ & 3 & 3 & 2 \\
DMSO added [vol. / vol.] & $0 ; 5$ & 45 & 0 & 5 \\
Cycles & $40,45,50,55$ & 0.04 & 45 & 45 \\
Ramp rate $\left[{ }^{\circ} \mathrm{C} / \mathrm{s}\right]$ & $0.11 ; 0.06 ; 0.04 ; 0.03$ & rs $2066845(\mathrm{G} 908 \mathrm{R})$ & 0.04 & 0.04 \\
qPCR-HRMA with unlabeled probe & & $/$ & $1: 5$ & $/$ \\
Primer asymmetry ratio & $1: 5,1: 10,1: 20$ & $/$ & 55 & $/$ \\
Cycles & $40,45,50,55$ & &
\end{tabular}

\subsection{PCR-HRMA optimization}

qPCR-HRMA was performed in 96-well plates on the LightCycler 4802.0 instrument (Roche, USA). The final reaction volume was $10 \mu \mathrm{L} ; 8 \mu \mathrm{L}$ of reaction master mix were added to $2 \mu \mathrm{L}$ of template DNA. Optimal qPCR-HRMA parameters were selected from experiments with the highest concordance between HRMA and PCR-RFLP genotypes (Table 3). Final DNA concentration ranged from $10-40 \mathrm{ng} / \mu \mathrm{L}$ as determined by absorbance at $260 \mathrm{~nm}$ on NanoDrop 2000 spectropho- tometer (ThermoScientific, USA). Cycling conditions were performed using the following protocol: initial denaturation at $95^{\circ} \mathrm{C}$ for $10 \mathrm{~min}$, followed by denaturation $\left(95^{\circ} \mathrm{C}, 15 \mathrm{~s}\right)$, annealing $\left(50-65^{\circ} \mathrm{C}, 10 \mathrm{~s}\right)$ and extension $\left(72^{\circ} \mathrm{C}, 15 \mathrm{~s}\right)$. Samples with known genotypes were used as reference and were run in triplicates for each of NOD2/CARD15 polymorphisms. Raw fluorescence data were analyzed with two algorithms given by the software provided with the LC480 instrument. In "Gene scanning" algorithm, raw fluorescence data were normalized, shifted and subtracted from a refer- 
ence melting curve to obtain difference plots. Here, differences in melting curve shapes were used to determine the sample genotypes. On the other hand "Tm calling" algorithm, is based on calculation of negative of first derivative of fluorescence data, where distinctive melting curve peaks and Tms (melting temperatures) were obtained to discriminate between different genotypes.

\subsection{Statistical analysis}

We used the two-sided Fisher's exact test to compare NOD2/CARD15 genotype and allele frequencies between control group and IBD patients. Statistical tests were calculated using SPSS 17.0 (SPSS Inc., Chicago, IL, USA) statistical package. Odds ratios (OR) and corresponding $95 \%$ confidence intervals (CI95\%) were calculated with SPSS 17.0 software. In all tests $p<$ 0.05 was considered to indicate statistical significance. Hardy-Weinberg equilibrium for genotype frequencies was checked in the control group.

\section{Results}

\subsection{Optimization and evaluation of $q P C R-H R M A$ assays for NOD2/CARD15 variants}

Optimized parameters for qPCR-HRMA NOD2/CA RD15 assays are summarized in Table 3.

\subsubsection{L1007fs}

HRM analysis in combination with "Gene scanning" algorithm of $217 \mathrm{bp}$ amplicon displayed three types of melting curves, which correlated with wild-type (wt/wt), heterozygous (C/wt) and mutant homozygous (C/C) genotypes (Fig. 1a). Two rare homozygous mutants were found by HRMA in CD patients, and were subsequently confirmed by PCR-RFLP. Genotyping results obtained from qPCR-HRMA were $100 \%$ concordant with results from PCR-RFLP.

\subsection{2. $G 908 R$}

With HRM analysis of $100 \mathrm{bp}$ amplicon in combination with "Gene scanning" algorithm we were able to discriminate between homozygotes and heterozygotes (Fig. 1b). Discrimination between homozygotes was achieved by introducing of unlabeled probe in combination with the "Tm calling" algorithm (Fig. 3). Unlabeled probe annealed to $\mathrm{C} / \mathrm{C}$ (mutant) and partially to $\mathrm{G} / \mathrm{C}$ amplicons and produced unique probe-amplicon melting transitions, which were used for genotype discrimination. As illustrated in Fig. 2 probe-amplicon melting transitions were observed between $63^{\circ} \mathrm{C}-68^{\circ} \mathrm{C}$ and amplicon-amplicon melting transitions were observed between $87^{\circ} \mathrm{C}-89^{\circ} \mathrm{C}$. A rare homozygous mutant $(\mathrm{C} / \mathrm{C})$ was found in $\mathrm{CD}$ patients, which was subsequently confirmed by PCR-RFLP. Genotyping results obtained from qPCR-HRMA were $100 \%$ concordant with results from PCR-RFLP.

\subsection{3. $R 702 W$}

As illustrated in Fig. 1c qPCR-HRMA assay for R702W DSA in combination with "Gene scanning" algorithm displayed two types of melting curve shapes that correlated to wild-type $(\mathrm{C} / \mathrm{C})$ and heterozygous $(\mathrm{C} / \mathrm{T})$ genotypes. No homozygous mutants $(\mathrm{T} / \mathrm{T})$ were found in patients or controls. Genotyping results obtained from qPCR-HRMA were $100 \%$ concordant with results from PCR-RFLP.

In total, DNA samples of 588 IBD patients and 256 healthy controls were successfully genotyped for NOD2/CARD15 DSAs by qPCR-HRMA and confirmed by PCR-RFLP.

In addition to previously mentioned SNPs, two other potential SNPs reported in the dbSNP database also map within the NOD2/CARD15 amplicons used in our experiments. First SNP rs58586167 is located 4 bases upstream of G908R polymorphism with non-validated status at the time of this study. The second SNP rs35285618 is a low frequency (MAF $=0.013$ ) SNP located 19 bases downstream of R702W polymorphism and was so far detected only in African Americans. To exclude potential interference with our HRMA assays, a PCR-RFLP analysis of these two SNPs was conducted in Slovenian IBD patients and in healthy controls. We found no individuals positive for any of the two polymorphisms, suggesting that these SNPs are either very rare or not present in the Slovenian population.

\subsection{Association analysis on Slovenian IBD patients}

We genotyped the samples of 588 Slovenian IBD patients and 256 healthy unrelated blood donors using PCR-RFLP and qPCR-HRMA methods. A group of 37 patients with indeterminate colitis (IC) was not included in statistical analysis as a separate group due to small sample size. Statistically significant association was found for L1007fs DSA in CD patients ( $p=0.001$, $\mathrm{OR}=3.011, \mathrm{CI} 95 \%=1.494-6.071)$, but not in UC patients $(p=0.504, \mathrm{OR}=0.885$, CI95\% $=0.334$ 2.346), compared to healthy controls (Table 4). Minor 
a

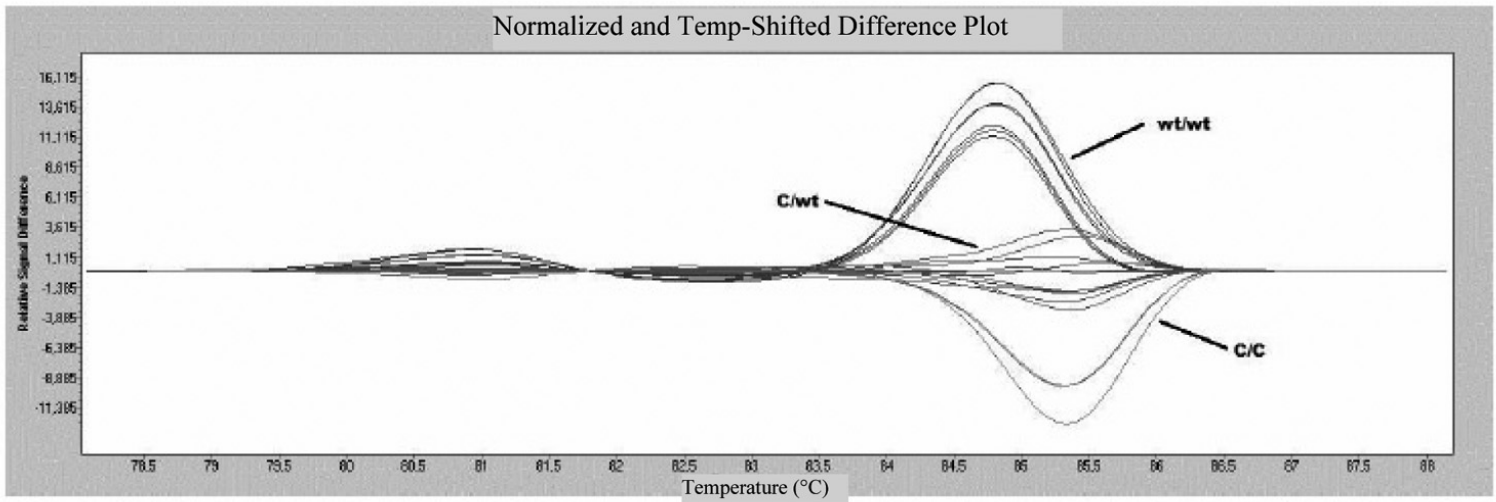

b

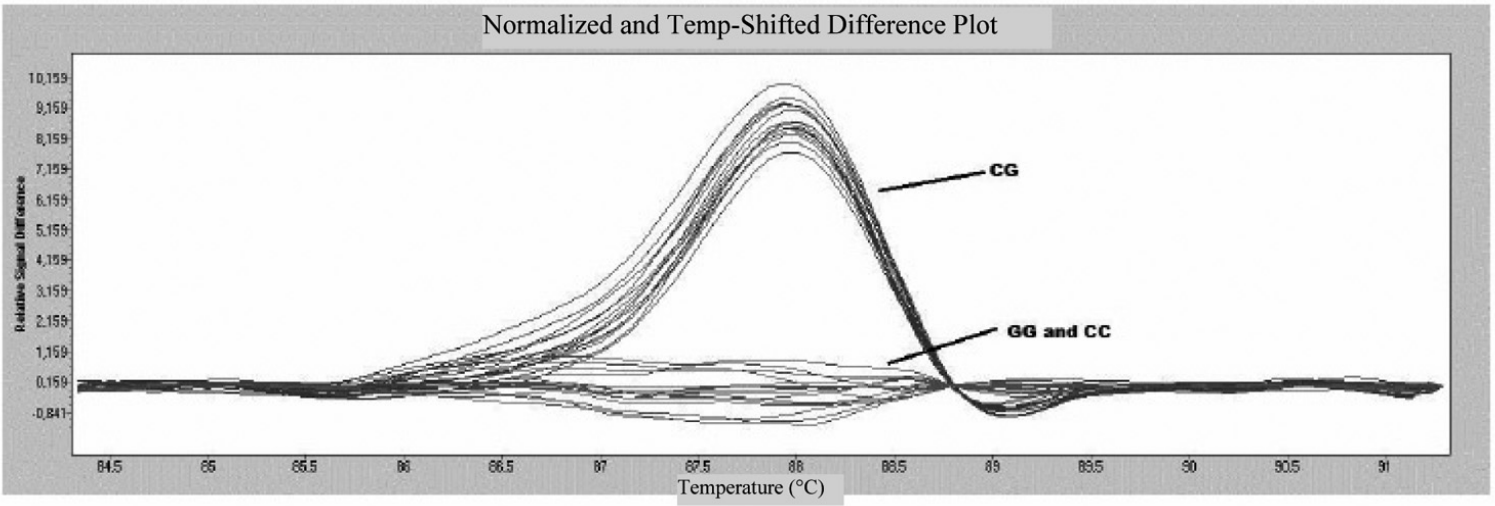

C

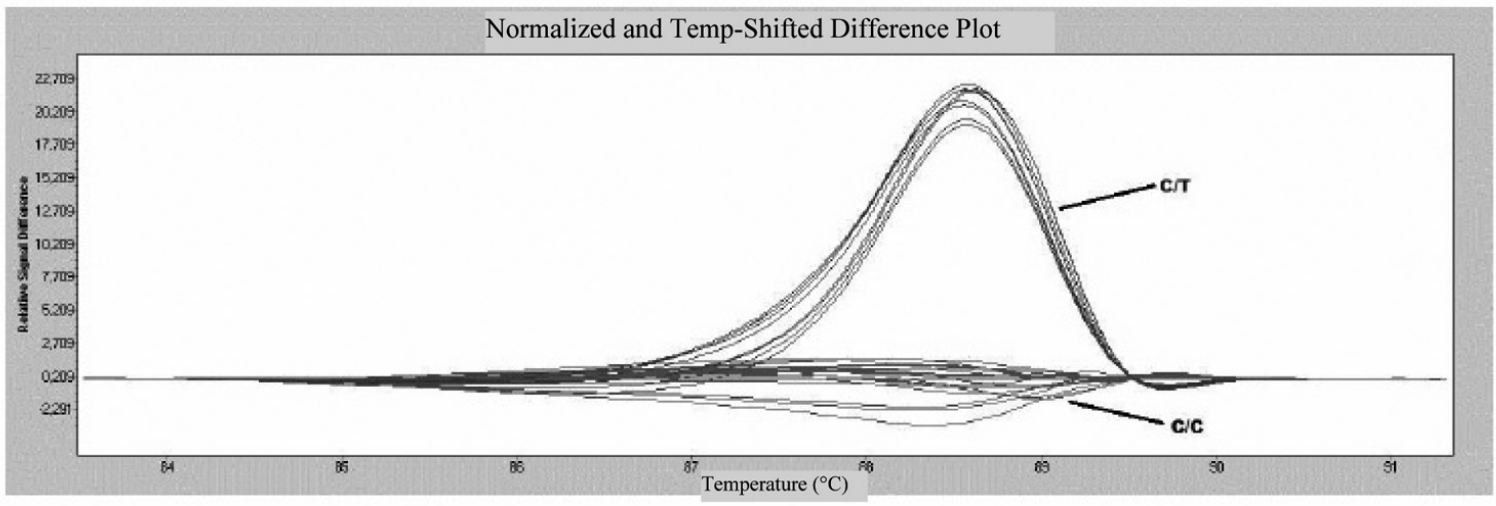

Fig. 1. Difference plots of NOD2/CARD15 polymorphisms. Difference plots were obtained subsequent to raw fluorescence data normalization, Tm-shift and subtraction from a reference melting curve by "Gene scanning" algorithm. a) L1007fs (rs2066847). Genotypes of L1007fs polymorphism were clearly distinguished and grouped into three groups. wt/wt represents melting curves of wild-type homozygotes, C/wt melting curves of heterozygotes and C/C melting curves of mutant homozygotes. b) G908R (rs2066845). Heterozygotes were unambiguously distinguished from both groups of homozygotes due to altered melting curve shapes. Differentiation of homozygotes was difficult because of similar melting curve shapes of G/G and C/C homozygotes. c) R702W (rs2066844). Wild-type homozygotes and C/T heterozygotes were clearly distinguished. No homozygous mutants (T/T) were found in our study. C/C represents wild-type homozygotes and $\mathrm{C} / \mathrm{T}$ heterozygotes.

allele frequency (MAF) of L1007fs polymorphism was $2 \%$ in control group, $5.9 \%$ in $\mathrm{CD}$ group and $1.8 \%$ in UC group. L1007fs MAF was also significantly higher in CD patients as compared to UC patients ( $p=0.001$, $\mathrm{OR}=3.404, \mathrm{CI} 95 \%=1.512-7.663)$. In case of G908R
DSA, we found statistically significant association in CD patients $\left(p=2.62 \times 10^{-4}, \mathrm{OR}=14.117, \mathrm{CI} 95 \%\right.$ $=1.884-105.799)$ and UC patients $(p=0.013$, OR $=$ 9.389$, CI95\% $=1.150-76.641)$ as compared to healthy controls. G908R MAF was $0.2 \%$ in control group, 
Table 4

Results of association analysis of NOD2/CARD15 DSAs in Slovenian IBD patients and healthy controls

\begin{tabular}{|c|c|c|c|c|c|c|c|c|c|}
\hline & \multicolumn{3}{|c|}{ L1007fs } & \multicolumn{3}{|c|}{ G908R } & \multicolumn{3}{|c|}{ R702W } \\
\hline & $\mathrm{C}$ & $\mathrm{CD}$ & $\mathrm{UC}$ & $\mathrm{C}$ & $\mathrm{CD}$ & $\mathrm{UC}$ & $\mathrm{C}$ & $\mathrm{CD}$ & $\mathrm{UC}$ \\
\hline Homozygotes (wt) & 237 & 311 & 188 & 252 & 330 & 184 & 238 & 323 & 185 \\
\hline Heterozygotes & 10 & 37 & 7 & 1 & 17 & 7 & 15 & 30 & 11 \\
\hline Homozygotes (mt) & 0 & 2 & 0 & 0 & 1 & 0 & 0 & 0 & 0 \\
\hline Total & 247 & 350 & 195 & 253 & 348 & 191 & 253 & 353 & 196 \\
\hline Homozygotes (wt) [\%] & 96.0 & 88.86 & 96.41 & 99.6 & 94.82 & 96.34 & 94.1 & 91.50 & 94.39 \\
\hline Heterozygotes $[\%]$ & 4.0 & 10.57 & 3.59 & 0.4 & 4.89 & 3.66 & 5.9 & 8.50 & 5.61 \\
\hline Homozygotes (mt) [\%] & 0 & 0.57 & 0 & 0 & 0.29 & 0 & 0 & 0 & 0 \\
\hline MAF & 0.02 & 0.059 & 0.018 & 0.002 & 0.027 & 0.018 & 0.03 & 0.042 & 0.028 \\
\hline$p$-value & & 0.001 & 0.504 & & $2.62 \times 10^{-4}$ & 0.013 & & 0.156 & 0.527 \\
\hline OR & & 3.011 & 0.885 & & 14.117 & 9.389 & & 0.450 & 0.945 \\
\hline CI95\% & & $1.494-6.071$ & $0.334-2.346$ & & $1.884-105.799$ & $1.150-76.641$ & & $0.773-2.729$ & $0.429-2.081$ \\
\hline
\end{tabular}

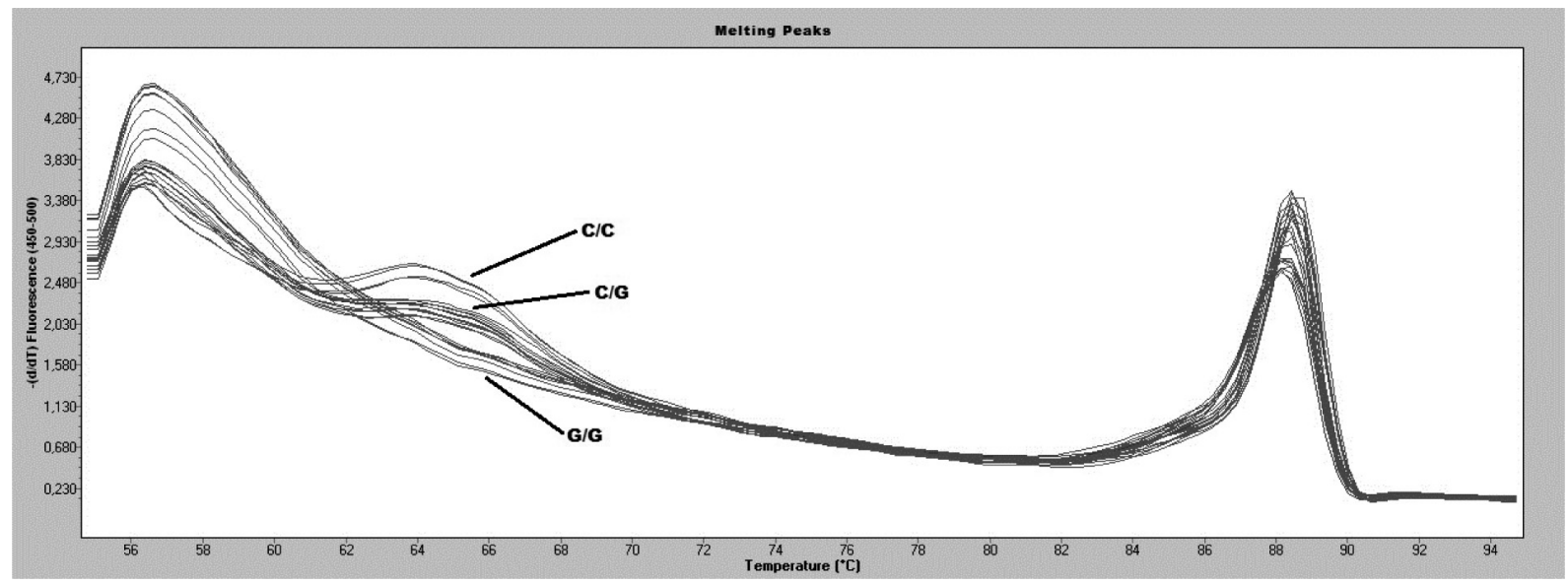

Fig. 2. Melting peaks of G908R (rs2066845) amplicon and unlabeled probe melting. Negative of first derivative of raw fluorescence data $(-\mathrm{dF} / \mathrm{dT})$ was calculated by "Tm calling" algorithm and presented on $\mathrm{y}-$ axis against temperature $(\mathrm{T})$ on $\mathrm{x}-$ axis. Unlabeled probe annealed to C/C (homozygous-mutant) and partially to heterozygous $\mathrm{G} / \mathrm{C}$ amplicons. This resulted in a unique probe-amplicon melting transitions $\left(62^{\circ} \mathrm{C}-68^{\circ} \mathrm{C}\right)$, which were used for differentiation of G908R genotypes. Differentiation of genotypes by amplicon melting was not possible, since the amplicon melting peaks were confined to a narrow temperature interval $\left(88.2^{\circ} \mathrm{C}-88.5^{\circ} \mathrm{C}\right)$.

$2.7 \%$ in CD patients and $1.8 \%$ in UC patients. We found no statistically significant association of R702W DSA with CD and UC patients. Detailed results of association analysis are summarized in Table 4. The frequency of carriers of any polymorphism was significantly higher in CD patients compared to healthy controls $\left(p=6.53 \times 10^{-5}, \mathrm{OR}=2.5, \mathrm{CI} 95 \%=1.551-4.028\right)$ and also when compared to UC patients $(p=0.004$, $\mathrm{OR}=1.944, \mathrm{CI} 95 \%=1.192-3.171)($ Table 5$)$. At least one of NOD2/CARD15 DSAs was found in 78/354 (22.03\%) CD patients, 25/197 (12.69\%) in UC patients and $26 / 256(10.15 \%)$ in healthy controls. Additionally, we found $9 / 354(2.54 \%)$ compound heterozygotes in CD patients and none in UC patients or in control group. In addition, mutant homozygotes for L1007fs and G908R polymorphisms were found only in group of $\mathrm{CD}$ patients.
Table 5

Prevalence of at least one NOD/CARD15 DSA in Slovenian IBD patients and controls

\begin{tabular}{lccc}
\hline \multicolumn{3}{c}{ At least one mutation } \\
\hline & $\mathrm{C}$ & $\mathrm{CD}$ & $\mathrm{UC}$ \\
\hline Any variant & 0.1015 & 0.2203 & 0.1269 \\
$p$-value & & $6.53 \times 10^{-5}$ & 0.243 \\
OR & & 2.500 & 1.286 \\
CI95\% & & $1.551-4.028$ & $0.717-2.304$ \\
\hline
\end{tabular}

OR, odds ratio; CI95\%, confidence interval 95\%; C, controls; CD, Crohn's disease; UC, ulcerative colitis.

\section{Discussion}

We have developed three qPCR-HRMA genotyping assays for NOD2/CARD15 DSAs and compared them to standard PCR-RFLP assays. As reported in previous studies $[19,20]$, we also observed that the success of 
Table 6

Minor allele frequencies of NOD2/CARD15 polymorphisms in European IBD patients and controls

\begin{tabular}{|c|c|c|c|c|c|c|c|c|c|c|}
\hline \multirow[b]{2}{*}{ European population } & \multirow[b]{2}{*}{ Authors (year) [Reference] } & \multicolumn{3}{|c|}{$\mathrm{R} 702 \mathrm{~W}$} & \multicolumn{3}{|c|}{ G908R } & \multicolumn{3}{|c|}{ L1007fs } \\
\hline & & $\mathrm{CD}$ & $\mathrm{UC}$ & $\mathrm{C}$ & $\mathrm{CD}$ & $\mathrm{UC}$ & $\mathrm{C}$ & $\mathrm{CD}$ & $\mathrm{UC}$ & $\mathrm{C}$ \\
\hline Belgium & Esters et al. (2004) [25] & 12.9 & 7.8 & 5.8 & 6.0 & 3.2 & 1.8 & 8.6 & 1.4 & 3.0 \\
\hline Croatia & Cukovic-Cavka et al. (2006) [26] & 13.9 & / & 5.5 & 4.4 & / & 1.1 & 11.8 & / & 4.4 \\
\hline Czech Republic & Hosek et al. (2008) [27] & 13.0 & 2.0 & 1.0 & 3.0 & 0.0 & 0.0 & 22.0 & 11.0 & 6.0 \\
\hline Denmark & Vind et al. (2005) [28] & 0.0 & / & 1.5 & 2.6 & / & 1.0 & 16.4 & I & 2.1 \\
\hline England & Ahmad et al. (2002) [29] & 12.5 & / & 5.2 & 3.3 & / & 1.4 & 9.4 & / & 1.6 \\
\hline Finland & Heliö et al. (2003) [30] & 3.3 & 1.5 & 1.8 & 0.6 & 0.0 & 0.0 & 4.8 & 3.0 & 1.7 \\
\hline France & Heresbach et al. (2004) [31] & 11.5 & / & 4.7 & 3.7 & I & 1.6 & 9.0 & / & 4.2 \\
\hline \multirow[t]{2}{*}{ Germany } & Hampe et al. (2002) [32] & 10.5 & / & 4.8 & 5.2 & l & 0.7 & 14.5 & I & 4.1 \\
\hline & Buning et al. (2004) [33] & 7.2 & 2.1 & 3.6 & 4.2 & 2.1 & 2.1 & 12.2 & 4.3 & 2.1 \\
\hline Greece & Gazouli et al. (2005) [34] & 10.0 & 7.1 & 1.0 & 14.2 & 13.5 & 3.5 & 17.9 & 3.5 & 6.0 \\
\hline \multirow[t]{2}{*}{ Hungary } & Buning et al. (2005) [35] & 7.1 & 3.1 & 2.6 & 3.0 & 1.6 & 1.2 & 10.8 & 2.3 & 2.2 \\
\hline & Nagy et al. (2005) [36] & 10.3 & / & 4.7 & 2.7 & / & 1.4 & 8.9 & / & 2.4 \\
\hline Iceland & Thjodleifsson et al. (2003) [37] & 0.0 & / & / & 0.0 & I & / & 0.0 & / & / \\
\hline Ireland & Bairead et al. (2003) [38] & 7.0 & / & 4.0 & 3.0 & / & 1.0 & 4.0 & / & 1.0 \\
\hline \multirow[t]{3}{*}{ Italy } & Giachino et al. (2004) [39] & 9.0 & 10.9 & 5.9 & 4.3 & 2.7 & 1.4 & 6.3 & 0.5 & 2.3 \\
\hline & Vavasori et al. (2004) [40] & 1.2 & I & 0.8 & 5.2 & / & 2.0 & 11.2 & / & 1.2 \\
\hline & Annese et al. (2004) [41] & 9.0 & / & 5.0 & 5.5 & / & 2.0 & 7.7 & I & 1.3 \\
\hline Netherlands & van der Linde et al. (2007) [42] & 8.8 & 4.7 & 5.9 & 6.1 & 0.0 & 0.7 & 11.0 & 2.3 & 1.9 \\
\hline Norway & Hampe et al. (2002) [32] & 4.3 & l & 2.8 & 0.9 & / & 1.2 & 2.6 & / & 1.2 \\
\hline Portugal & Ferreira et al. (2005) [43] & 12.2 & / & 4.0 & 2.8 & / & 1.3 & 6.8 & / & 1.6 \\
\hline Scotland & Arnott et al. (2004) [44] & 7.2 & 2.6 & 5.5 & 1.8 & 2.0 & 0.2 & 4.6 & 3.0 & 1.4 \\
\hline Slovakia & Bartosova et al. (2009) [45] & 9.9 & 2.86 & 8.97 & 3.96 & 1.43 & 1.92 & 16.83 & 8.57 & 5.77 \\
\hline Slovenia & This study & 5.1 & 3.0 & 3.0 & 2.6 & 1.7 & 0.2 & 5.9 & 2.2 & 2.0 \\
\hline Spain & Nunez et al. (2004) [46] & 6.7 & / & 5.8 & 4.5 & / & 1.0 & 4.5 & / & 1.0 \\
\hline Serbia & Protic et al. (2008) [47] & 20.6 & 1.5 & 14.8 & 5.3 & 0.0 & 0.0 & 15.3 & 7.7 & 0.0 \\
\hline Switzerland & Ruegg et al. (2004) [48] & 5.7 & I & I & 2.8 & I & I & 4.7 & I & I \\
\hline
\end{tabular}

qPCR-HRMA genotyping strongly depends on careful optimization of PCR parameters and adjustment of DNA concentration to similar values. Although there were some reports [12,21,22] on normalization (premelting, post-melting, sensitivity) and Tm-shift parameters for the LightCycler software, so far no guidelines how to approach these parameters were reported. In our case as well, we observed that the optimal normalization and Tm-shift parameters should be established arbitrarily and determined experimentally. In the course of our work, we have observed that short amplicons reduce the poor discrimination of homozygous samples as was reported previously [11]. Heterozygotes were clearly distinguished from homozygotes in all three studied NOD2/CARD15 polymorphisms. Additionally, we were able to distinguish homozygous wild-types and mutants for R702W and L1007fs polymorphisms. According to previous reports, HRMA with unlabeled probe was used when the Tm differences were insufficient to distinguish between different homozygotes [4,23]. In case of NOD2/CARD15 G908R polymorphism the $\mathrm{G}$ :C transition created insufficient differences in Tm. Unambiguous discrimination of homozygous samples was eventually achieved after the introduction of unlabeled probe. In a previous study [24], it was reported that HRMA has limited sensitivity for single nucleotide insertion-deletion variants located immediately adjacent to mononucleotide runs. In this study, L1007fs (rs2066847), an insertion of a cytosine adjacent to 3 cytosine repeat was fully detectable for heterozygous and homozygous mutant genotypes.

Previous studies show, that there is a strong evidence for regional heterogeneity within European populations in the contribution of NOD2/CARD15 to disease susceptibility, which may reflect to differing founder populations (Table 6). Our study is the first report of the distribution of three major NOD2/CARD15 DSAs in Slovenian IBD patients and healthy controls. We found that NOD2/CARD15 DSAs are as frequent (22.03\%) in Slovenian CD patients and healthy controls (10.15\%) as in Hungary [36], Italy [49], Netherlands [50], Portugal [28], Denmark [28], Scotland [44] and Switzerland [48], and higher than in Finland [30], and lower than in Serbia [47] and Croatia [26]. Similar to majority of European studies we also report a significant association of L1007 and G908R with CD patients. The difference of MAFs between Slovenian CD patients and Slovenian healthy controls was highest for L1007fs polymorphism (3.9\%) as compared to G908R polymorphism $(2.4 \%)$ and R702W polymorphism (2.1\%), 
suggesting that L1007fs plays most important role in NOD2/CARD15 CD - associated risk in Slovenian population, thus placing Slovenians in the European average. On the other hand, the highest difference of MAFs between CD patients and controls was reported for the R702W polymorphism in Portuguese [43] (8.2\%) and French [31] (6.8\%) populations. The MAF of R702W in Slovenians was slightly increased in CD patients and decreased in UC patients, though it showed no significant association with $\mathrm{CD}$ and UC patients vs. healthy controls as was also the case in the majority of studies conducted in European populations. Interestingly, we found the association of G908R with Slovenian UC patients which was however previously reported only in Greek [34] and Scottish [44] studies. The MAF of G908R in Slovenian UC patients is similar to that reported in several other European studies (Table 6) $[35,45,51,52]$, but lower frequency of this polymorphism was detected in healthy controls in Slovenian population as compared to other European populations. Our findings may indicate a possible role of NOD2/CARD15 polymorphisms in UC patients, implicating a need for further replication in a larger cohort. Four percent of $\mathrm{CD}$ patients were homozygote or compound heterozygote for NOD2/CARD15 polymorphisms, yet we have not detected a single compound heterozygote or homozygote individual among healthy controls suggesting NOD2/CARD15 compound heterozygote and homozygote status may be particularly reliable and highly specific marker for risk prediction for developing CD in Slovenian population.

In conclusion, the results of this study suggest that HRM analysis yields significant savings on analysis time and costs although costs for the development and optimization of the new HRM assays should be also taken into a consideration. HRMA has proven as a simple high-throughput technique for screening for polymorphisms of NOD2/CARD15 gene. We report significant association of L1007fs with CD and G908R with $\mathrm{CD}$ and UC. We have successfully implemented NOD2/CARD15 HRMA assays, which may contribute to the development of genetic profiles for risk prediction of developing $\mathrm{CD}$ and for differential diagnosis of CD vs. UC.

\section{Acknowledgements}

We are thankful to all patients and healthy individuals for their willingness to participate in this study. We thank Ivo Ferkolj, Pavel Skok, Andreja Ocepek and Sil- vo Koder for assistance in collecting samples. We also thank Katja Repnik for sample preparation and technical assistance. This work was supported by Slovenian Research Agency Grant No. J3-2175.

Competing interests: none declared.

\section{References}

[1] J.C. Barrett et al., Genome-wide association defines more than 30 distinct susceptibility loci for Crohn's disease, Nat Genet 40 (2008), 955-962.

[2] C. Miceli-Richard, S. Lesage, M. Rybojad et al., CARD15 mutations in Blau syndrome, Nat Genet 29 (2001), 19-20.

[3] E. Holler, G. Rogler, H. Herfarth et al., Both donor and recipient NOD2/CARD15 mutations associate with transplantrelated mortality and GvHD following allogeneic stem cell transplantation, Blood 104 (2004), 889-894.

[4] J. Montgomery, C.T. Wittwer, R. Palais and L. Zhou, Simultaneous mutation scanning and genotyping by high-resolution DNA melting analysis, Nat Protocols 2 (2007), 59-66.

[5] A.O. Crockett and C.T. Wittwer, Fluorescein-labeled oligonucleotides for real-time PCR: Using the inherent quenching of deoxyguanosine nucleotides, Anal Biochem 290 (2001), 8997.

[6] C.N. Gundry, J.G. Vandersteen, G.H. Reed, R.J. Pryor, J. Chen and C.T. Wittwer, Amplicon melting analysis with labeled primers: A closed-tube method for differentiating homozygotes and heterozygotes, Clin Chem 49 (2003), 396-406.

[7] R.H.A.M. Vossen, E. Aten, A. Roos and J.T. den Dunnen, High-resolution melting analysis (HRMA) - More than just sequence variant screening, Hum Mut 30 (2009), 860-866.

[8] C.F. Taylor, Mutation scanning using high-resolution melting, Biochem Soc Trans 37 (2009), 433-437.

[9] C.T. Wittwer, High-resolution DNA melting analysis: advancements and limitations, Hum Mut 30 (2009), 857-859.

[10] B.L. Smith, C.P. Lu and J.R. Alvarado Bremer, Highresolution melting analysis (HRMA): a highly sensitive inexpensive genotyping alternative for population studies, Mol Ecol Res 10 (2010), 193-196.

[11] M. Liew, M. Seipp, J. Durtschi, R.L. Margraf, S. Dames, M. Erali, K. Voelkerding and C.T. Wittwer, Closed-tube genotyping without labeled probes: A comparison between unlabeled probe and amplicon melting, Am J Clin Pathol 127 (2007), 341-348.

[12] P.A. Norambuena, J.A. Copeland, P. Krenkova, A. Štambergova and M. Macek, Jr., Diagnostic method validation: High resolution melting (HRM) of small amplicons genotyping for most common variants in the MTHFR gene, Clin Biochem 42 (2009), 1308-1316.

[13] E. Takano, G. Mitchell, S. Fox and A. Dobrovic, Rapid detection of carriers with BRCA1 and BRCA2 mutations using high resolution melting analysis, BMC Cancer 8 (2008), 59.

[14] W.J. Chen, W.J. Dong, X.Z. Lin, M.T. Lin, S.X. Murong, Z.Y. Wu and N. Wang, Rapid diagnosis of spinal muscular atrophy using high-resolution melting analysis, BMC Medical Genetics 10 (2009), 45-48.

[15] U. Potočnik, I. Ferkolj, D. Glavač and M. Dean, Polymorphisms in multidrug resistance 1 (MDR1) gene are associated with refractory Crohn disease and ulcerative colitis, Genes Immun 5 (2004), 530-539. 
[16] Human Experimentation: Code of Ethics of W.M.A, $\mathrm{Br}$ Med J 2 (1964), 177.

[17] S. Rozen and H.J. Skaletsky, Primer3 on the WWW for general users and for biologist programmers, in: Bioinformatics Methods and Protocols: Methods in Molecular Biology, S. Krawetz and S. Misener, eds, Humana Press, Totowa, 2000, pp. 365-386.

[18] N. Peyret, P.A. Seneviratne, H.T. Allawi and J. SantaLucia, Nearest-Neighbor Thermodynamics and NMR of DNA Sequences with Internal A.A, C.C, G.G, and T.T Mismatches, Biochem 38 (1999), 3468-3477.

[19] G. Millat, V. Chanavat, C. Rodriguez-Lafrasse and R. Rousson, Rapid, sensitive and inexpensive detection of SCN5a genetic variations by high resolution melting analysis, Clin Biochem 42 (2009), 491-499.

[20] V. Dagar, C.W. Chow, D.M. Ashley and E.M. Algar, Rapid detection of SMARCB1 sequence variation using high resolution melting, BMC Cancer 9 (2009), 437-461.

[21] I. Rapado, S. Grande, E. Albizua, R. Ayala, J.A. Hernandez, M. Gallardo, F. Gilsanz and J. Martinez-Lopez, Highresolution melting analysis for JAK2 exon 14 and exon 12 mutations, J Mol Diag 11 (2009), 155-161.

[22] V. Ugo, S. Tondeur, M.L. Menot et al., Interlaboratory development and validation of a HRM method applied to the detection of JAK2 exon 12 mutations in polycythemia vera patients, Plos 5 (2010), 8893-8901.

[23] L. Zhou, A.N. Myers, J.G. Vandersteen, L. Wang and C.T. Wittwer, Closed-tube genotyping with unlabeled oligonucleotide probes and a saturating DNA dye, Clin Chem 50 (2004), 13281335.

[24] S. Garritano, F. Gemignani, S.V. Tavtigian et al., Determining the effectivness of high resolution melting analysis for SNP genotyping and mutation scanning at the TP53 locus, BMC Genetics 10 (2009), 5-36.

[25] N. Esters, M. Pierik, K. van Steen, S. Vermeire et al., Transmission of CARD15 (NOD2) variants within families of patients with inflammatory bowel disease, Am J Gastroenterol 99 (2004), 299-305.

[26] S. Cukovic-Cavka, S. Vermeire, I. Hrstic et al., NOD2/ CARD15 mutations in Croatian patients with Crohn's disease: prevalence and genotype-phenotype relationship, Eur J Gastroenterol Hepatol 18 (2006), 895-899.

[27] J. Hosek, L. Bartosová, P. Gregor et al., Frequency of representative single nucleotide polymorphisms associated with inflammatory bowel disease in the Czech Republic and Slovak Republic, Folia Biol 54 (2008), 88-96.

[28] I. Vind, A. Vieira, L. Hougs et al., NOD 2/CARD15 gene polymorphisms in Crohn's disease: a genotype-phenotype analysis in Danish and Portugese patients and controls, Digestion 72 (2005), 156-163.

[29] T. Ahmad, A. Armuzzi, M. Bunce et al., The molecular classification of the clinical manifestations of Crohn's disease, Gastroenterology 122 (2002), 854-866.

[30] T. Helio, L. Halme, M. Lappalainen et al., CARD15/NOD2 gene variants are associated with familialy occuring and complicated forms of Crohn's disease, Gut 52 (2003), 558-562.

[31] D. Heresbach, V. Gicquel-Douabin, B. Birebent et al., NOD2 /CARD15 gene polymorphisms in Crohn's disease: a genotype-phenotype analysis, Eur J Gastroenterol Hepatol 16 (2004), 55-62.

[32] J. Hampe, J. Grebe, S. Nikolaus, C. Solberg et al., Association of NOD(CARD15) genotype with clinical course of Crohn's disease: a cohort study, Lancet 359 (2002), 1661-1665.
[33] C. Buning, J. Genschel, S. Buhner et al., Mutations in the NOD2/CARD15 gene in Crohn's disease are associated with ileocecal resection and are risk factor for reoperation, Aliment Pharmacol Ther 19 (2004), 1073-1078.

[34] M. Gazouli, G. Mantzaris, A. Kotsinas et al., Association between polymorphisms in the toll-like receptor 4, CD14, and CARD15/NOD2 and inflammatory bowel disease in the Greek population, World J Gastroenterol 11 (2005), 681-685.

[35] C. Buning, T. Molnar, F. Nagy, J. Lonovics et al., NOD2 /CARD15 gene polymorphism in patients with inflammatory bowel disease: is Hungary different?, World J Gastroenterol 11 (2005), 407-411.

[36] Z. Nagy, O. Karadi, G. Rumi et al., Crohn's disease is associated with polymorphism of Card 15/ NOD2 gene in a Hungarian population, Ann N Y Acad Sci 1051 (2005), 45-51.

[37] B. Thjodleifsson, G. Sigthorsson, N. Cariglia et al., Subclinical intestinal inflammation: an inherited abnormality in Crohn's disease relatives?, Gastroenterology 124 (2003), 1728-1737.

[38] E. Bairead, D.L. Harmon, A.M. Curtis et al., Association of NOD2 with Crohn's disease in homogenous Irish population, Eur J Hum Genet 11 (2003), 237-244.

[39] D. Giachino, M.M. Van Duist, S. Regazzo et al., Analysis of the CARD15 variants R702W, G908R and L1007fs in Italian IBD patients, Eur J Hum Genet 12 (2004), 206-212.

[40] P. Vavassori, P. Borgiani, L. Biancone et al., CARD15 mutation analysis in an Italian population: Leu1007fsinsC but neither Arg702Trp nor Gly908Arg mutations are associated with Crohn's disease, Inflamm Bowel Dis 10 (2004), 116-121.

[41] V. Annese, G. Lombardi, F. Perri et al., Variants of CARD15 are associated with an aggressive clinical course of Crohn's disease: an IG-IBD study, Am J Gastroenterol 100 (2005), 84-92.

[42] K. van der Linde, P.P.C. Boor, J.J. Houwing-Duistermaat et al., CARD15 mutations in Dutch familial and sporadic inflammatory bowel disease and an overview of European studies, Eur J Gastroenterol Hepatol 19 (2007), 449-459.

[43] A.C. Ferreira, S. Almeida, M. Tavares et al., NOD2/CARD15 and TNFA, but not IL1B and IL1RN, are associated with Crohn's disease, Inflamm Bowel Dis 11 (2005), 331-339.

[44] I.D. Arnott, E.R. Nimo, H.E. Drummond et al., NOD2/ CARD15, TLR4 and CD14 mutations in Scottish and Irish Crohn's disease patients: evidence for genetic heterogeneity within Europe? Gennes Immun 5 (2004), 417-425.

[45] L. Bartosova, M. Kolorz, J. Hosek, D. Dvorackova, P. Loucka, V. Zboril, M. Batovsky and M. Bartos, Genove polymorfismy jako predispozicni factor IBD - jejich vztah ke klinicke manifestaci a farmakoterapii onemocneni, Ces a Slov Gastroent a Hepatol 63 (2009), 265-274.

[46] C. Nunez, M. Barreiro, J.E. Dominguez-Munoz et al., CARD15 mutations in patients with Crohn's disease in a homogenous Spanish population, Am J Gastroenterol 99 (2004), 450-456.

[47] M.B. Protic, S.T. Pavlovic, D.Z. Bojic et al., CARD15 genepolymorphisms in Serbian patients with Crohn's disease: genotype-phenotype analysis, Eur J Gastroenterol Hepatol 20 (2008), 978-984.

[48] C. Ruegg, M. Hersberger, B. Wusk et al., Detection of the Arg702Trp, Gly908Arg, and Leu1007fsinsC polymorphisms of the NOD2/CARD15 gene by real-time PCR melting curve analysis, Clin Chem Lab Med 42 (2004), 494-498.

[49] V. Annese, O. Palmieri, A. Latiano, S. Ardizzone, F. Castiglione, M. Cottone et al., Frequency of NOD2/CARD15 variants in both sporadic and familial cases of Crohn's disease 
274 M. Mitrovič and U. Potočnik / High-resolution melting curve analysis for high-throughput genotyping of NOD2/CARD15 mutations

across Italy. An Italian group for inflammatory bowel disease study, Dig Liver Dis 36 (2004), 121-124.

[50] R.K. Linskens, R.C. Mallant-Hent, L.S. Murillo, B.M. von Blomberg, B.Z. Alizade and A.S. Pena, Genetic and serological markers to identify phenotypic subgroups in a Dutch Crohn's disease population, Dig Liver Dis 36 (2004), 29-34.

[51] A. Andruilli, V. Annese, A. Latiano, O. Palmieri, P. Forti- na, S. Ardizzone et al., The frame-shift mutation of the NOD2/CARD15 gene is significantly increased in ulcerative colitis: an IG-IBD study, Gastroenterol 126 (2004), 625-627.

[52] A.P. Cuthbert, S.A. Fisher, M.M. Mirza, K. King, J. Hampe, P.J. Croucher et al., The contribution of NOD2 gene mutations to the risk and site of disease in inflammatory bowel disease, Gastroenterol 122 (2002), 867-874. 


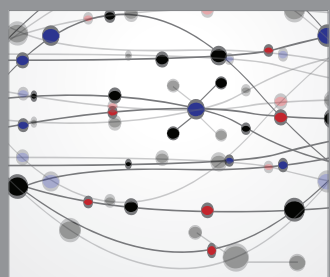

The Scientific World Journal
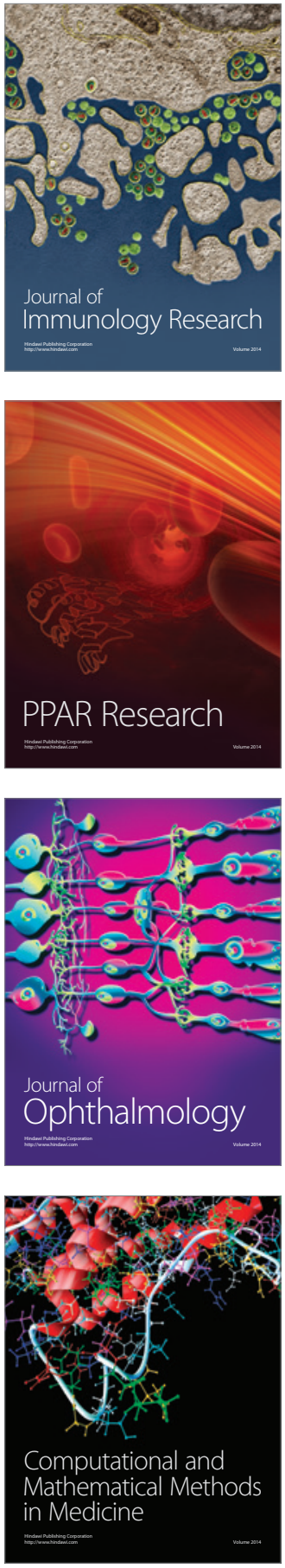

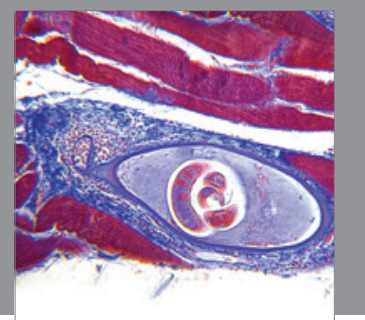

Gastroenterology

Research and Practice
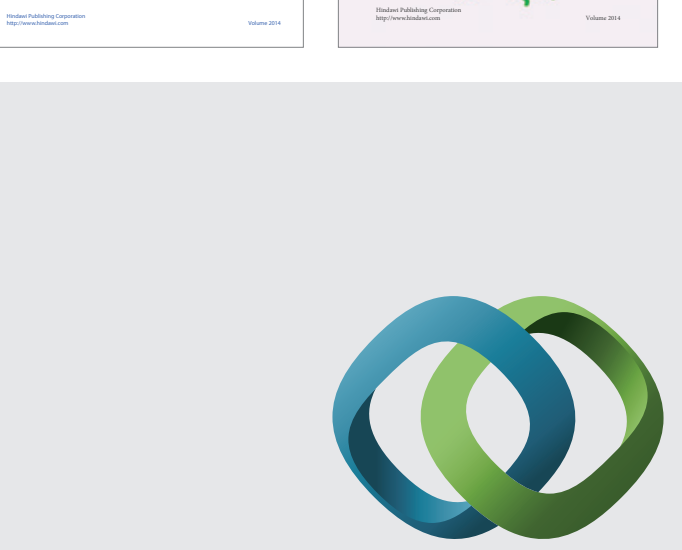

\section{Hindawi}

Submit your manuscripts at

http://www.hindawi.com
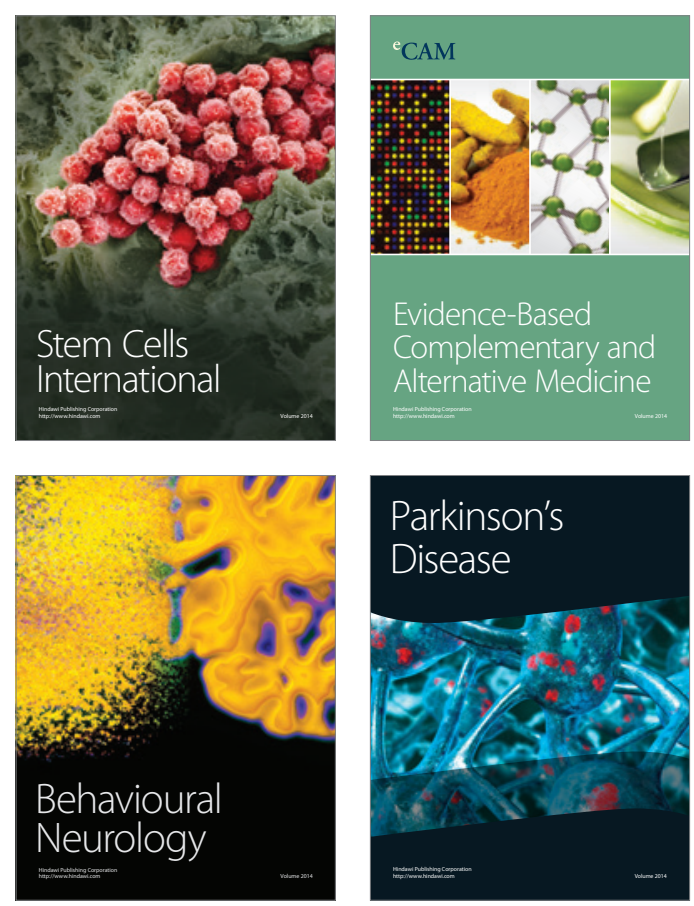

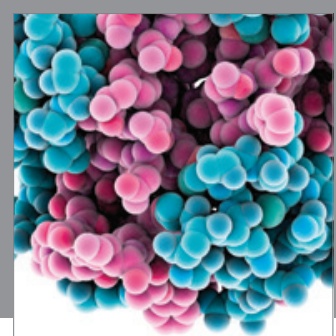

Journal of
Diabetes Research

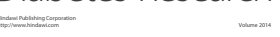

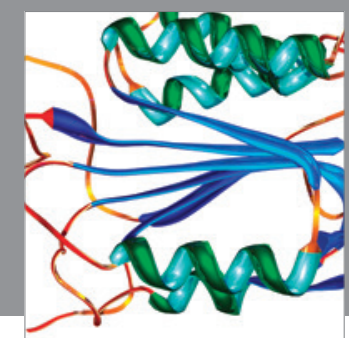

Disease Markers
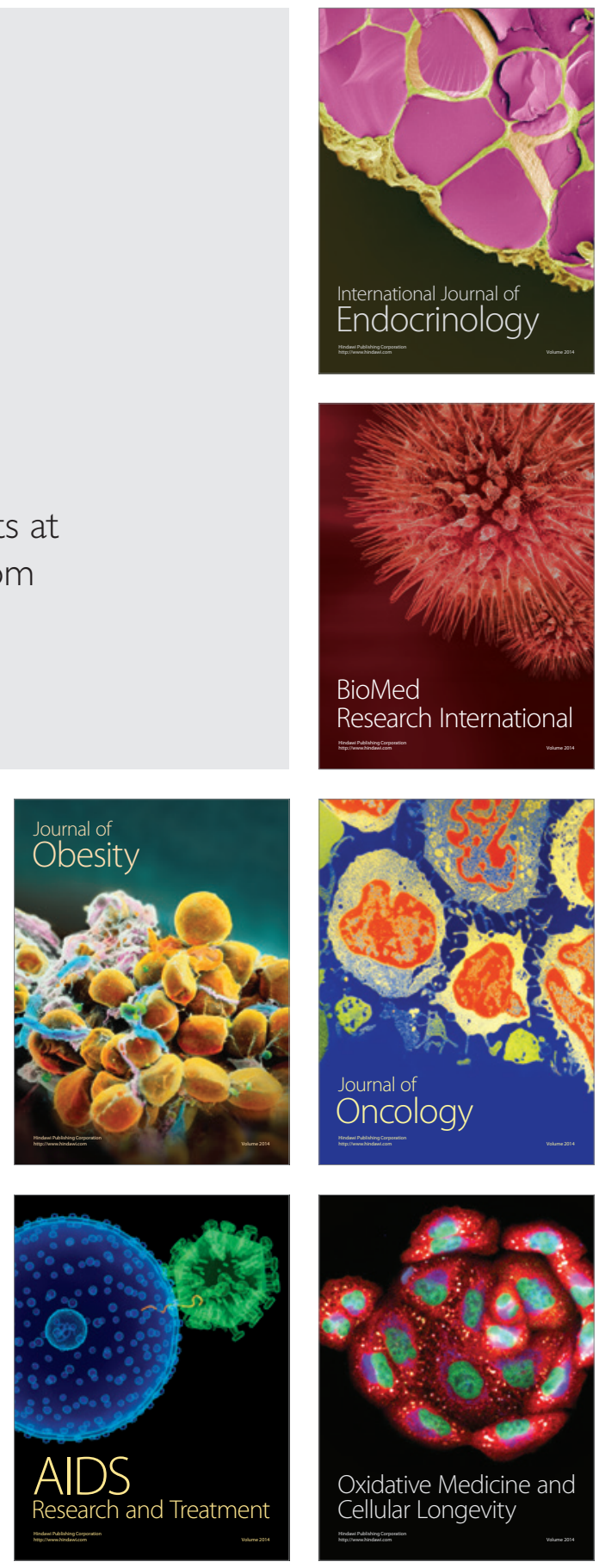